\title{
VETERINARY CURRICULUM REVIEW AND RENEWAL AT THE UNIVERSITY OF PERADENIYA, SRI LANKA
}

\author{
Nayana Wijayawardhane ${ }^{1^{*}}$, Chanaka Rabel ${ }^{1}$, Siril Ariyarathne ${ }^{1}$, Harishchandra \\ Abeygunawardena ${ }^{1}$, Lachlan McIntyre ${ }^{2}$ and Tim Parkinson ${ }^{2}$
}

\author{
${ }^{\prime}$ Faculty of Veterinary Medicine and Animal Science, University of Peradeniya, Sri Lanka \\ ${ }^{2}$ School of Veterinary Science, Massey University, Palmerston North, New Zealand
}

\begin{abstract}
SUMMARY: A major review of the Bachelor of Veterinary Science (BVSc) program at University of Peradeniya, Sri Lanka was undertaken under the umbrella of the Office International des Epizooties (OIE; World Organisation for Animal Health) Veterinary Education Twinning Program with the partnership of Massey University, New Zealand. The review process started with widespread consultation amongst the Sri Lankan veterinary profession and other stakeholders to identify areas in which changes were needed to the current competencies of veterinary graduates. The review was undertaken as a formal process of the University of Peradeniya, in alignment with the requirements and expectations of the Sri Lanka Qualifications Framework (SLQF). Content was aligned with the recommendations of the OIE on the competencies of graduating veterinarians and projections of national and global standards for the veterinary profession for at least the next two decades. Pedagogical revision has been based upon current best practices in veterinary medical education worldwide. Revision of clinical teaching has similarly aimed to ensure that graduates are well-equipped to meet the diverse expectations of animal owners in Sri Lanka. It has aimed to increase the scope of clinical teaching by drawing upon the breadth of clinical resources that are available throughout the country. Key changes to the program included the extension of its duration by one academic year in order to allow for a year of uninterrupted clinical teaching, alignment and amalgamation of related material, the introduction of problem-based learning modules, a significant reduction in lecture content with a parallel increase in tutorial and practical contents, elaboration of several courses related to industries that have recently gained improved importance in the country (e.g. equine, aquaculture, poultry), and introduction of several new courses to cover topics that had not been adequately covered previously. Finally, a program-long thread of material relating to the professional, ethical and inter-personal behaviour of veterinarians has been introduced. Presentation of the revised curriculum to the profession in Sri Lanka has been met with a high level of enthusiasm and a willingness to participate in its clinical teaching.
\end{abstract}

\section{INTRODUCTION}

Veterinary education was established in Sri Lanka with the opening of the veterinary degree program at the University of Ceylon in 1947. Since then, progressive iterations of the qualification have seen it vested in the Faculty of Veterinary Medicine and Animal Sciences (FVMAS), at the University of Peradeniya (UP) as a 4-year, bachelors level qualification (Bachelor of Veterinary Science: BVSc) that leads directly to registration with the Veterinary Council of Sri Lanka (see http://vet.pdn.ac.lk/ general.php for a more detailed history). The present curriculum, initially designed in 1992, was a modification of the program at the Royal Veterinary College, London, at that time. A major review of the program was undertaken in 2000, with emphases on improvement and integration of courses in animal health and production sciences. Minor reforms have been made since 2000 to help the curriculum to better meet local needs, but without a systematic review of the entire program. In 2010, such a systematic review was initiated, aimed at broad-basing the BVSc curriculum, improving teaching and training resources and methods, and expanding research and development capacity and outreach activities, but that curriculum did not come to implementation.

There have also been changes in patterns of animal ownership and livestock farming in Sri Lanka that have necessitated change to the BVSc curriculum. Changes to livestock farming have seen the emergence of aquaculture, poultry farming and dairying as major economic activities. Concurrent changes in the socioeconomic status of middleincome pet owners have resulted in increased expectations for the breadth and standard of companion animal veterinary services. These changes have resulted in demands upon the veterinary school to broaden its curriculum by introducing a wider range of specialisations whilst also ensuring greater practical competency in basic 
veterinary procedures, and incorporation of modern, evidence-based treatment and disease prevention methodologies. Such material has been incorporated into the BVSc degree, but often on a piecemeal fashion. Moreover, the consequence of continual addition of new material has, inevitably, been curricular drift and expansion, with the outcomes of factual overload, an imbalance between theoretical and practical training, and assessment overload.

Furthermore, there have been significant changes to tertiary education in general, and veterinary education in particular over the same period. The content of veterinary degree programs has become increasingly defined by international expectations around the capabilities of veterinary graduates at the point of their entry to the veterinary workforce (Welsh et al., 2009), notably the graduate competency statements of organisations such as the Royal College of Veterinary Surgeons (RCVS, 2017) and the World Organization for Animal Health (Office International des Epizooties: OIE; OIE, 2012). In turn, these competency statements define both the content and teaching of the curriculum that students study. Concurrent changes in tertiary educational practice have seen an increased emphasis upon outcome-based education (Davies, 2003), with student-centred, active-learning and constructivist pedagogies; which, in the context of veterinary education, translates into a greater emphasis on practical skills versus detailed theoretical knowledge, extended clinical teaching in the latter stages of the program, inclusion of clinical activities through all stages of the program, and a greatly increased emphasis on learning in the affective (e.g. communication, professionalism) and psychomotor/ technical domains (Dale et al., 2008).

The final major contribution to the need for a comprehensive review of the BVSc program was the review of the Performance of Veterinary Services (PVS) of Sri Lanka by the OIE. That review included recommendations for changes in veterinary services, which would need to be underpinned by changes to veterinary education. As a follow-up of this evaluation, the OIE facilitated UP and Massey University, New Zealand, to embark on an ambitious veterinary twinning partnership. This paper reports the process of curriculum review that was followed, and describes the key features of the new curriculum that was developed through that partnership.

\section{PROCESSES AND METHODS}

The program was funded by the New Zealand Aid Program administered by the New Zealand Ministry of Foreign Affairs and Trade. It was approved and endorsed by OIE under their Veterinary Education Twinning Program (OIE, 2013). There were five key steps in the process of curriculum review and revision:

1. Determining the governance structure

2. Developing needs assessment and selfevaluation reports

3. Developing the graduate profile and Day-1 competencies of the BVSc degree program

4. Defining the specific aims of curriculum review and revision

5. Designing the curriculum

\section{1) Governance structure}

Governance of the OIE twinning program was through a committee that comprised the Deans of the veterinary faculties, OIE delegates and stakeholders of the relevant government ministries from Sri Lanka and New Zealand, and the Project Manager.

Governance of the development of the curriculum was through the Faculty Board of the FVMAS. The Board appointed a Curriculum Revision Committee (CRC), and charged it with terms of reference and a timeline of completion. The CRC reported progress to the Faculty Board on a regular basis.

\section{2) Developing needs assessment and self-evaluation reports}

In order to identify the expectations of veterinary graduates by animal owners and the veterinary profession in Sri Lanka, a series of 'stakeholder' consultations were undertaken. Selected stakeholders included representatives of livestock and allied industries, farmers, veterinarians (including private practitioners, government veterinarians and recent graduates) and senior veterinary students. Key findings for the curriculum review were excessive factual content and limited practical and problem-solving content in the curriculum resulting in the production of graduates with inadequate practical, problem-solving, and diagnostic skills. Further, changing patterns of employment towards the companion animal sector needed to be reflected in the curriculum, whilst more competence and confidence with farm animals was needed.

The academic staff of the FVMAS concurrently created a Self-Evaluation Report (SER) of the BVSc, based upon the accreditation criteria of the Australasian Veterinary Boards Council (AVBC, 2016). This report covered most aspects of the activities of the FVMAS, including its physical 
infrastructure, caseload, staff profile, curriculum and assessment, student management, and research profile. The SER was used as the basis of a gap analysis to provide a guide to the FVMAS of areas in which development or investments were needed. Areas of strength were the qualifications of the teaching staff, and the overall research capability of the faculty. Areas of weakness included low clinical caseload and lack of ready access to livestock. An inventory of physical infrastructure that would need development to support a revised curriculum was also identified.

\section{3) Developing the program learning outcomes of the BVSc degree program}

The FVMAS, again in consultation with the stakeholders of the veterinary profession in Sri Lanka, developed a series of competencies required of veterinary graduates. The process of stakeholder consultation was rigorous, with meetings with many individuals and groups, and with iterative progression in the development of the competencies in response to feedback upon successive drafts. Overarching these discussions was the 'graduate profile' of the UP comprising the general competencies of any of its graduates. The curriculum also had to meet the requirements of the Sri Lanka Qualifications Framework (SLQF; Ministry of Higher Education, 2012). The abovementioned sources of input were used to design the Graduate Outcomes (GOs) and Day 1 Graduate Competencies for the degree, or, in other words, to define the knowledge, skills, competencies and professional behaviour of the veterinary graduates. In the next phase of the process, these outcomes had to be formally mapped to the content and assessment of each unit of study as well as to the program overall. Importantly, as these outcomes included competencies in professional and technical skills, appropriate teaching and assessment methods for such non-cognitive learning also had to be incorporated into the mapping process (excerpts from the mapping of one course are provided in Annex 1).

\section{4) Defining the teaching and learning environment}

Faculty and stakeholders also identified that a revised curriculum needed to be aligned with the instructional principles of modern veterinary curricula. These included reducing the load of formally-instructed content, increasing the emphasis on the professional behaviour and technical/manual skills, use of outcome-based, student-centred instructional approaches, whilst ensuring constructive alignment of topics, contents, objectives, teaching and learning methods and assessments. Contextualisation was to be emphasised, particularly by ensuring integration between different academic disciplines and between academic and clinical disciplines. Engagement, particularly with livestock, was to be promoted by ensuring that students have clinical exposure and access to handle animals from the first semester of the program.

Clinical instruction was to be improved by extending the program by two semesters that could be used entirely for clinical work. Doing so would also make better use of the available clinical caseload, which was underutilised; and would also allow for more systematic planning of students' clinical activities.

\section{5) Designing the curriculum}

It is widely recognised that veterinary and medical curricula have to be designed 'backwards' from the GOs of a program into the specific content that contributes to those outcomes (Prideaux, 2003; Hodgson and Ilkiw, 2017). Failure to do so inevitably results in curricular drift and expansion, with resultant factual overload, an imbalance between theoretical and practical training, and assessment overload (van de Mortel and Bird, 2010; Wilson et al., 2012). The graduate profile, Day 1 competencies and program learning outcomes described above were used to create a template from which the titles, course learning outcomes, teaching and learning activities and assessment activities of each course that would make up the new program were derived.

The final design elements that overarched the development of the content of the curriculum are shown in Table 1. In addition, the CRC used the SLQF norms (Ministry of Higher Education, 2012) for calculating student workload, and for balancing hours allocated for lectures, practical classes, student-centred learning and self-study, and assessment. Teaching and learning activities were not only to be formally aligned with learning outcomes, but both also had to be formally aligned with assessment activities in terms of content and assessment methodology. 
Table 1: Key areas of development for the BVSc curriculum at the University of Peradeniya

\begin{tabular}{|c|c|}
\hline Intended developments & Adoption in the curriculum \\
\hline $\begin{array}{l}\text { Aligned with globally accepted best practices } \\
\text { and standards in veterinary education, } \\
\text { including volume of learning, scope, content, } \\
\text { pedagogy and assessments }\end{array}$ & $\begin{array}{l}\text { Adopt OIE Day } 1 \text { veterinary competencies in framing } \\
\text { program learning outcomes. } \\
\text { Adopt outcome-based education, supplemented with } \\
\text { tools such as problem-based learning and student- } \\
\text { centered pedagogies and assessments. } \\
\text { Extend the BVSc program to five academic years to } \\
\text { accommodate abovementioned alterations and to align } \\
\text { with international benchmarks for undergraduate } \\
\text { veterinary degree programs. }\end{array}$ \\
\hline $\begin{array}{l}\text { Clinical education that includes the latest } \\
\text { clinical and treatment methodologies }\end{array}$ & $\begin{array}{l}\text { Introduce an additional final year devoted for clinical } \\
\text { training and outbound externships. } \\
\text { Introduce problem-based learning sessions as an } \\
\text { 'Integrated Veterinary Sciences' spine which runs } \\
\text { throughout the theoretical instruction in Years 1-4 of the } \\
\text { program. }\end{array}$ \\
\hline $\begin{array}{l}\text { Fully prepared to serve the rapidly } \\
\text { transforming farm animal industry }\end{array}$ & $\begin{array}{l}\text { Introduce animal production courses early in the } \\
\text { curriculum and offer production and health as integrated } \\
\text { courses. }\end{array}$ \\
\hline $\begin{array}{l}\text { Develop skills in management, business, } \\
\text { professional and entrepreneurial skills }\end{array}$ & $\begin{array}{l}\text { Strengthen training in livestock economics, business } \\
\text { administration, human resource management and } \\
\text { veterinary extension. } \\
\text { Introduce a program on professional studies. }\end{array}$ \\
\hline $\begin{array}{l}\text { Development of competencies in veterinary } \\
\text { public health and allied disciplines }\end{array}$ & $\begin{array}{l}\text { Strengthen key courses of interest to government } \\
\text { veterinary services, particularly veterinary public } \\
\text { health, epidemiology and statistics. }\end{array}$ \\
\hline $\begin{array}{l}\text { Improved international recognition for the } \\
\text { veterinary degree }\end{array}$ & $\begin{array}{l}\text { Adopt international best practices and standards and } \\
\text { seek international accreditation, i.e. extension of the } \\
\text { degree program to } 10 \text { semesters including a 'lecture- } \\
\text { free' final year dedicated for clinical work. }\end{array}$ \\
\hline
\end{tabular}




\section{RESULTS}

Overview of revised curriculum

An overview of the new curriculum is shown in Figure 1. The duration of the program has been increased from 8 semesters to 10 semesters, and content-based teaching will be completed by the end of Year 4, so that Year 5 can be devoted entirely to 'hands-on' clinical learning. In accordance with the expectations of the SLQF, there has been a significant net reduction in lecture-based material and a commensurate increase in practical material. The curriculum has largely retained a progression from pre-clinical subjects through para-clinical subjects to clinical subjects, although there are now introductory clinical courses from Semester 3 (Year 2) of the program. Related subjects have been brought together and, as far as possible, integrated. Thus, the disciplines of anatomy and physiology have been conjoined into a single course, infectious diseases have been brought into close alignment, clinical and gross pathology aligned, and systems pathology aligned with systems medicine.

\begin{tabular}{|c|c|c|c|c|c|c|c|c|c|c|c|c|c|c|c|}
\hline & \multicolumn{15}{|c|}{ Credit Hours } \\
\hline Semester & 1 & 2 & 4 & 5 & 6 & 7 & 8 & 9 & 10 & 11 & 12 & 13 & 14 & 15 & 16 \\
\hline 1 & IVSI & \multicolumn{5}{|c|}{ Anatomy and Physiology I } & \multicolumn{3}{|c|}{ Biochemistry I } & \multicolumn{2}{|c|}{ Animal Science I } & \multicolumn{2}{|c|}{ Prof. Studies I } & \multicolumn{2}{|c|}{ English I } \\
\hline 2 & IVS II & \multicolumn{5}{|c|}{ Anatomy and Physiology II } & \multicolumn{3}{|c|}{ Biochemistry II } & \multicolumn{3}{|c|}{ Animal Science II } & $\begin{array}{c}\text { Prof. } \\
\text { Studies II }\end{array}$ & \multicolumn{2}{|c|}{ English II } \\
\hline 3 & IVS III & $\begin{array}{l}\text { Introduction to Vet. } \\
\text { Clinical Practice }\end{array}$ & \multicolumn{3}{|c|}{ Anatomy and Physiology III } & \multicolumn{3}{|c|}{ Vet. Bacteriology and Mycology } & \multicolumn{2}{|c|}{ Immunology } & \multicolumn{4}{|c|}{ Animal Science III } & \\
\hline 4 & INS IV & \multicolumn{2}{|c|}{$\begin{array}{l}\text { Clinical Pathology and } \\
\text { Diagnostics }\end{array}$} & \multicolumn{2}{|c|}{ Vet. Pathology I } & \multicolumn{2}{|c|}{ Vet. Virology } & \multicolumn{2}{|c|}{ Vet. Parasitology I } & \begin{tabular}{|c|} 
Vet. \\
Pharmacology 1
\end{tabular} & \multicolumn{4}{|c|}{ Animal Science IV } & \\
\hline 5 & IVSV & \multicolumn{3}{|c|}{ Companion Animal Health I } & \multicolumn{2}{|c|}{ Vet. Pathology II } & \multicolumn{2}{|c|}{ Vet. Parasitology II } & \multicolumn{3}{|c|}{ Vet. Pharmacology II } & \multicolumn{4}{|c|}{ Farm Animal Production and Health I } \\
\hline 6 & INS VI & \multicolumn{2}{|c|}{ Companion Animal Health II } & Research I & \multicolumn{2}{|c|}{ Vet. Pathology III } & \multicolumn{2}{|c|}{ Epidemiology } & \multicolumn{2}{|c|}{ Biostatistics } & $\begin{array}{l}\text { Econol } \\
\text { Veteri }\end{array}$ & $\begin{array}{l}\text { ics for } \\
\text { Irians }\end{array}$ & \multicolumn{3}{|c|}{$\begin{array}{l}\text { Farm Animal Production and } \\
\text { Health II }\end{array}$} \\
\hline 7 & IVS VII & \multicolumn{2}{|c|}{ Companion Animal Health III } & \multicolumn{3}{|c|}{ Research II } & \multicolumn{3}{|c|}{ Veterinary Public Health I } & \multicolumn{3}{|c|}{$\begin{array}{l}\text { Aquaculture and Aquatic Animal } \\
\text { Health }\end{array}$} & \multicolumn{3}{|c|}{$\begin{array}{l}\text { Farm Animal Production and } \\
\text { Health III }\end{array}$} \\
\hline 8 & IVS VIII & $\begin{array}{l}\text { Wild Animal Health } \\
\text { and Management }\end{array}$ & Reser & irch III & $\begin{array}{r}\text { Veterina } \\
\text { Hea }\end{array}$ & $\begin{array}{l}\text { ry Public } \\
\text { lth II }\end{array}$ & Veterin & Extension & $\begin{array}{r}\text { Principles } \\
\text { Mana }\end{array}$ & $\begin{array}{l}\text { of Business } \\
\text { gemnt }\end{array}$ & $\begin{array}{l}\text { Equine } \mathrm{H} \\
\text { Mana }\end{array}$ & $\begin{array}{l}\text { alth and } \\
\text { ment }\end{array}$ & $\begin{array}{r}\text { Poultry Path } \\
\text { Heal }\end{array}$ & $\begin{array}{l}\text { lology and } \\
\text { lth }\end{array}$ & \\
\hline 9 & & Comapr & on and $W$ & ild Animal C & inics I & & & & & & Farm Ani & al Clinics & & & \\
\hline 10 & Comapr & ion and Wild Animal Cl & iics II & & & & & nship & & & & & Farm Anima & I Clinics II & \\
\hline
\end{tabular}

Figure 1. Revised and approved curriculum for the new BVSc degree program.

IVS: Integrated Veterinary Sciences (problem-based learning)

The distribution of teaching of clinical disciplines throughout the program has undergone major changes. After two early courses that deal with clinical examination, clinical pathology and the underpinning 'ologies' (anaesthesia, imaging, principles of surgery), medicine and surgery have been amalgamated on a systems basis, using companion animals as the 'type' species.

The livestock/food animal curriculum has undergone an even more radical change. To meet the aspirations of the CRC to achieve early and on-going engagement of students with food animals, there are courses in the basics of animal husbandry and management systems from the first semester of the program which, importantly, contain substantial elements of farm visits (including smallholder farms) and animal handling. Thereafter, in Year 2, there are courses that cover aspects of animal science that pertain to veterinarians, followed by species-based course in food animal health and production. It was decided that species was a more appropriate basis upon which to structure food animal health teaching than the body-system basis that was used for companion animals. The final two semesters of formal instruction on livestock (Semesters 7 and 8) contain capstone courses on the health and production of farmed aquatic and poultry species. Horses, as a relatively minor species in Sri Lanka, are also covered in a similar capstone course. 
The aspiration for integration between the various disciplines that compose the program has been addressed through formal processes of horizontal (i.e. within an academic year) and vertical (i.e. between academic years) alignment. To better formalise the process, each semester contains a short 'Integration' course, taught by classical problembased learning pedagogies, in which students apply basic scientific principles on solving complex clinical problems. These problems are tailored to the stage of the program, and, particularly in Years 1 and 2 , are designed to create clinical relevance for the preclinical material.

The program as a whole was aligned with the Day 1 competencies of the OIE (OIE, 2012). Wherever possible, the learning outcomes associated with these competencies were incorporated into discipline-based courses. For example, zoonotic diseases were largely embedded within the infectious disease courses. Other OIE competencies fitted less well within such structures, so the revised program contains specific courses on epidemiology, biostatistics and veterinary public health/food hygiene.

\section{Orientation program, English language and professional skills}

Lack of synchrony among different 'batches' (cohorts/years) of students had been a long-standing cause of difficulty for the BVSc program. This has emanated from the lack of consistency in the dates of registration of new entrants by the University Grants Commission (UGC) from year-to-year. A decision was taken to fix the date of commencement of Semester 1 every year (and, hence, of all other semesters thereafter) by allowing the duration of the orientation program (pre-vet courses) to be flexible. Non-GPA English language-courses are provided during the orientation program and first two semesters, with the objective of enhancing students' general and technical English skills so that those who did not have their secondary education in the English medium can cope with the language demands of Year 1 teaching.

Socialisation into the veterinary profession is further developed through formal Year 1 courses in 'Professional Studies' and through a thread of related material that is interweaved through the subsequent theoretical, practical and clinical courses. Professional Studies covers material as wide-ranging and diverse as client communication (an OIE requirement: OIE, 2012), interpersonal skills, self-care and professional ethics. Veterinary business skills, although a 'subset' of professional studies, was allocated its own course in Year 4 of the program.

\section{Clinical skills}

The most profound changes have taken place in clinical rotations. In the present curriculum, students work in the university's veterinary clinics for $1 / 2$ to $3 / 4$ of each day during the second semester of Year 4 (only) of the program, and at irregular times elsewhere. This arrangement did not allow either the caseload presented to the Veterinary Teaching Hospitals (VTHs) or that available through the Farm Animal Ambulatory Clinic (FAAC) roster, to be properly used for teaching, resulting in inadequate hands-on clinical exposure. In order to improve students' clinical skills at graduation; hence, an ambitious final year program was devised that would be spent entirely in clinics. Students will work full days in the clinics and be on roster for out-of-hours emergencies, weekend work, etc., under the direction of clinical staff. Small animal clinical exposure will be augmented by elective placements in high-quality private clinics. Likewise, the food animal rosters will include the existing FAAC, a reinforced equine roster, and placements in the various intensive livestock industries (Figure 2). Placements in industry were desirable to ensure that graduates were familiar with all of the species of importance to livestock farming in Sri Lanka, some of which were either not readily available to the FAAC or were not accessible in the context of commercial farming practice. Meetings held with key enterprises in the pig, poultry and dairy industries were met with enthusiastic offers of placements for students within those industries. Hence, compulsory externships will take place on poultry and dairy farms, under the direction of supervising veterinarians: who, by intention, will have been trained in the principles of teaching and assessing Workplace Integrated Learning. Learning outcomes have been developed for each rotation, primarily to ensure that each student has undertaken (at least) the minimum procedures and activities that are defined for the program: i.e. that each student has achieved a defined minimum of clinical and procedural capability. 


\begin{tabular}{|c|c|c|c|}
\hline Semester 9 & & Semester 10 & \\
\hline Course & $\begin{array}{l}\text { Duration } \\
\text { (weeks) }\end{array}$ & Course & $\begin{array}{l}\text { Duration } \\
\text { (weeks) }\end{array}$ \\
\hline \multirow{2}{*}{$\begin{array}{l}\text { Companion Animal Clinical } \\
\text { Medicine Roster (CACM) }\end{array}$} & \multirow{2}{*}{2} & CACM & 1 \\
\hline & & CACS & 1 \\
\hline \multirow{2}{*}{$\begin{array}{l}\text { Companion Animal Clinical } \\
\text { Surgery Roster (CACS) }\end{array}$} & \multirow{2}{*}{2} & CAA & 1 \\
\hline & & WLCAW & 1 \\
\hline \multirow{2}{*}{$\begin{array}{l}\text { *Companion Animal Ancillary } \\
\text { Roster }(\mathrm{CAA})\end{array}$} & \multirow{2}{*}{2} & FAA & 1 \\
\hline & & FARE & 1 \\
\hline \multirow{2}{*}{$\begin{array}{l}\text { Wildlife and Companion Animal } \\
\text { Wards Roster (WLCAW) }\end{array}$} & \multirow{2}{*}{2} & $\mathrm{P} \& \mathrm{P}$ & 1 \\
\hline & & N\&A & 1 \\
\hline $\begin{array}{l}\text { Farm Animal Ambulatory Roster } \\
\text { (FAA) }\end{array}$ & 2 & $\begin{array}{l}\text { Externship } 1 \\
\text { (Dairy) }\end{array}$ & 2 \\
\hline $\begin{array}{l}\text { Farm Animal Reproduction and } \\
\text { Equine Roster (FARE) }\end{array}$ & 2 & $\begin{array}{l}\text { Externship } 2 \\
\text { (Poultry) }\end{array}$ & 2 \\
\hline Poultry and Pig Roster (P\&P) & 2 & $\begin{array}{l}\text { Externship } 3 \\
\text { (Elective } \S)\end{array}$ & 2 \\
\hline $\begin{array}{l}\text { Necropsy and Abattoir Roster } \\
\text { (N\&A) }\end{array}$ & 2 & $\begin{array}{l}\text { Externship } 4 \\
\text { (Elective§) }\end{array}$ & 2 \\
\hline Total & 16 & & 16 \\
\hline
\end{tabular}

Figure 2: Clinical rotations for Year 5 of the BVSc degree program. Rotations are in two- or one-week blocks, as illustrated

* Companion Animal Ancillary Roster: Pharmacy, Diagnostic Laboratory, Continuous Monitoring Unit and Emergency Critical Care

$\S$ Elective Externships: Choice of Companion Animal Practice, Zoo \& Wildlife, Aquaculture, Equine, Feed Industry, Pharmaceutical Industry, Research, Veterinary Investigation Centre, Swine Practice, Farm Animal Practice, Dairy, Poultry (Breeder and Hatchery) 


\section{Decompressing teaching hours}

One of the major objectives of the curriculum review was to 'decompress' the teaching program. By adding an extra year to the revised program, an additional 30 weeks of teaching (equivalent to approximately 1,200 hours) became available, allowing the excessively compressed clinical teaching to be spread over the entire $5^{\text {th }}$ year, in turn freeing up time in the $4^{\text {th }}$ year. The changes to the allocation of time to different teaching modalities subsequent to this decompression program are summarised in Table 2.

Table 2: Time allocated for different learning activities as a proportion of total hours in the previous and new curricula

\begin{tabular}{|c|c|c|c|c|c|c|c|c|}
\hline \multirow[b]{2}{*}{$\begin{array}{l}\text { Total } \\
\text { Timetable } \\
\text { Hours }\end{array}$} & \multirow[b]{2}{*}{$\begin{array}{l}\text { Face to } \\
\text { Face } \\
\text { Teaching }\end{array}$} & \multirow[b]{2}{*}{$\begin{array}{c}\text { Time } \\
\text { Available for } \\
\text { Independent } \\
\text { Learning }\end{array}$} & \multicolumn{3}{|c|}{ Lecture Room-based Learning } & \multicolumn{3}{|c|}{ Practical Learning } \\
\hline & & & Lectures & $\begin{array}{c}\text { Tutorials } \\
\text { and } \\
\text { Discussions }\end{array}$ & Totals & $\begin{array}{l}\text { Labs, } \\
\text { Practical and } \\
\text { Field Work }\end{array}$ & Clinical & Totals \\
\hline
\end{tabular}

\begin{tabular}{|c|c|c|c|c|c|c|c|c|c|c|}
\hline \multirow{2}{*}{$\begin{array}{l}\text { Previous } \\
\text { curriculum }\end{array}$} & Hours & 4800 & 3543 & 1257 & 1918 & 122 & 2040 & 866 & 637 & 1503 \\
\hline & $\begin{array}{l}\% \text { of } \\
\text { curriculum }\end{array}$ & & $74 \%$ & $26 \%$ & $40 \%$ & $3 \%$ & $43 \%$ & $18 \%$ & $13 \%$ & $31 \%$ \\
\hline \multirow{2}{*}{$\begin{array}{l}\text { New } \\
\text { curriculum }\end{array}$} & Hours & 6000 & 3871 & 2129 & 1076 & 552 & 1628 & 748 & 1495 & 2243 \\
\hline & $\begin{array}{l}\% \text { of } \\
\text { curriculum }\end{array}$ & & $65 \%$ & $35 \%$ & $18 \%$ & $9 \%$ & $27 \%$ & $12 \%$ & $25 \%$ & $37 \%$ \\
\hline
\end{tabular}

$\%$ Change from Previous

to New Curriculum

$-13 \% \quad+35 \% \quad-55 \% \quad+262 \% \quad-36 \% \quad-31 \%$

$+88 \%+19 \%$

Rather than allowing teaching time in Years 1-4 to expand to fill the newly-available time, there was a concurrent rationalisation of content and teaching methodology. Content volume was managed primarily by ensuring that only that content was included which is directly aligned to learning outcomes. Additionally, material that was obsolete, redundant or unintentionally repeated in different courses were identified and omitted. Consistent with the intention of the CRC to move the program from passive to active learning, a great deal of lecture content was replaced with active learning methods such as tutorials, discussion and problem-based learning. The net result of these changes was a reduction in the total lecture time by nearly 900 hours (55\% reduction), while increasing active learning time by over 400 hours (262\% increase). Together, these resulted in a reduction of classroom-based teaching of over 400 hours. Some of this time was used for practical/field work teaching, but, again, redundant or low-value practical teaching was also eliminated, resulting in a cutback in such teaching. The major beneficiary of this paring back of teaching time was clinical teaching, which increased from about 640 to 1500 hours ( $88 \%$ increase; Table 2 ).

The opportunity was also taken to align the allocation of face-to-face teaching hours and selfstudy hours with the guidelines of the SLQF. Briefly, these guidelines stipulate minimum ratios of selfstudy to teacher-student contact hours, and formal acknowledgement of the self-study time that students have to devote to assessment activities. In the previous curriculum, $74 \%$ of the timetable was contact time, leaving only $26 \%$ of the timetable hours for independent learning activities. In the new curriculum, even when the increase in clinical teaching is taken into account, there is $35 \%$ more timetable hours available for independent learning than in its predecessor.

\section{Review and monitoring}

Before the curriculum was advanced to the stage of seeking formal approval by the UGC, it was first introduced to the Sri Lanka veterinary profession in workshops held in Peradeniya. There was a high level 
of acceptance of the new program expressed by the participants at those workshops, accompanied by suggestions of how the proposed content could be improved by minor modifications. Where feasible, these were addressed in the final draft of the curriculum.

Introduction of a new curriculum requires formal processes for its monitoring and modification during the period of its implementation. Each course is, for the first three years of their delivery, being monitored through student-facing mechanisms such as feedback surveys and university-facing mechanisms such as pass rates and progression rates. It is intended that, if these processes, or reflections by academic staff, identify areas that need remediation, such modifications will be made.

\section{DISCUSSION}

Recent years have seen rapid evolution of the range of employment opportunities for veterinarians, including traditional areas of practice and government service, as well as a wide range of nontraditional roles at national and global levels (Pritchard, 1988). In Sri Lanka, new areas of veterinary services include wildlife and zoo animals, aquaculture and poultry, dairy self-sufficiency, and a burgeoning veterinary public health sector. Emergence and re-emergence of endemic and transboundary animal diseases and zoonoses has necessitated capacity building in animal disease diagnosis and surveillance (Hinchcliffe, 2015). Further, rapidly expanding poultry (Schwabenbauer and Rushton, 2007) and dairy (Ranaweera, 2007) sectors, with more commercialization, have demanded veterinary manpower services with many complementary competencies such as human resources and business management, extension, information technology, communication, marketing and public relations (Burt, 2017). Concurrently, all veterinary schools worldwide have become mandated to comply with the prescriptions of the OIE for veterinary education(OIE 2013).

The present review process has attempted to address these changes to the veterinary profession in Sri Lanka. Curriculum review is a many-facetted activity, that not only requires the garnering of expectations of traditional and non-traditional stakeholders of veterinary services, but also those of educationalists, national and international regulators and the students themselves. Hence, the present review started with widespread consultation amongst the Sri Lankan veterinary profession and other stakeholders to identify areas in which changes were needed to complement competencies displayed by veterinary graduates. This step between the collection of stakeholders' commentary and the development of curriculum content is arguably the most critical to the entire review process. Thus, the key design activity of modern veterinary curricula is planning its contents to ensure that graduates have achieved the knowledge, skills, competencies and behaviours that are required for entry to the profession. In other words, GOs have to be defined (Bok and Jaarsma, 2017), and thereafter a blueprint for the content is created from those GOs (Newble et al., 2005; Inzana, 2017). The GOs that underpin the revised curriculum present in this paper are available in full at https://vet.pdn.ac.lk/sitefiles/Handbook_2020.pdf (p.25).

Use of these GOs allowed the revised curriculum to break out of the mould of traditional veterinary curricula, which are largely limited to the cognitive domain ('knowledge'), taught on a discipline-by-discipline basis, progress from 'basic science' through to clinical, and use clinical caseload in a largely unplanned manner (i.e. teaching is based on 'what walks through the door'; Harden et al., 1984; Parkinson, 2017). The learning domains are largely related to replicative knowledge ('knows that'). By contrast, more modern veterinary curricula give greater emphasis to the affective (professional and personal behaviours) and psychomotor (technical and manual skills) domains, integrate material between disciplines at the point of delivery, endeavour to achieve clinical engagement from the earliest stages of the program, and have planned clinical exposure to ensure that all identified core clinical competencies are covered during the program. Learning domains are likely to be at the higher orders of learning taxonomies (Miller, 1990; Anderson and Krathwohl, 2001). A key component of modern curricula is that they generally devote at least one year of study to practical clinical instruction, in authentic clinical workplaces such as a teaching hospital or veterinary clinical practices.

The existing curriculum was identified as being overloaded in terms of student workload, contact teaching hours and assessment. The lack of a mechanism to identify repetition, overlap and excessive detail contributed significantly to this overload. Students exhibited most of the hallmarks of 
learners who have teaching and assessment overload, such as shallow learning, short-term retention of material and an emphasis upon the display of replicative knowledge rather than problem-solving and synthetic skills (Biggs and Tang, 2011). It was clear to the CRC that reduction of factual overload was necessary to improve learning and retention of information. Managing these factors became feasible once clear GOs had been identified and curriculum blueprinting had been undertaken. In that way, the CRC could ensure that all courses had fullyarticulated constructive alignment of topics, contents, objectives, ILOs, teaching and learning methods and assessments (Danielson and Hecker, 2017) with the GOs. Perhaps even more importantly, the FVMAS had identified the need for a change in the overall pedagogical environment of the program: which should be an outcome-based, student-centred, constructivist approach to the curriculum.

The decision to increase the duration of the program from 8 to 10 semesters (i.e. to allow an entirely clinical final year) was pivotal. The decision was demanding upon both the FVMAS staff and the MU twinning partners, as it was by no means certain whether the Faculty would be able to do so. Indeed, many alternatives or half-way-houses were discussed en route, before it was recognised that it would be difficult to meet all (or indeed any) of the other aspirations for the revised program without doing so. In the end, the FVMAS persevered with seeking the additional teaching time and, once that decision was made, and the requisite permissions from the university and higher education authorities were attained, the key tenets of the review (i.e. curriculum 'space' and a clinical, lecture-free final year) could progress.

There were, of course, many challenges to providing the clinical material to sustain an entire year of clinical teaching. Caseload in both the companion animal VTH and the FAAC could provide for much of the teaching requirements, but there were areas that they could not sustain. Thus, the primary accession caseload of the VTH was adequate, but the caseload of more complex material was not. Likewise, the FAAC could provide caseload from the local livestock sector, but not in intensively-farmed species or aquaculture. The CRC decided to seek to augment its own clinical resources by seeking access to privately-owned, specialist small animal practices, and to livestock industries and the clinical activities of the government's Department of Animal
Production and Health. Similar issues are commonly encountered by veterinary schools, and using a 'mixed' model, in which clinical teaching is partly delivered through the VTH and partly delivered through contractual or informal relationships with non-university clinical services, is widely recognized as the means of providing adequate clinical caseload (Parkinson, 2017). Presentation of these proposals to the veterinary profession has been met with a high level of willingness to participate in clinical teaching of the extended final year.

\section{CONCLUSION}

The BVSc curriculum at UP has been reviewed during an OIE-endorsed twinning program between the University of Peradeniya and Massey University. The review was underpinned by an extensive program of consultation with the veterinary profession and other stakeholders and users of veterinary services in Sri Lanka. The content of the revised program has been based upon a set of 'graduate outcomes' that were derived from these consultations: these have taken into consideration not only the knowledge that is required of a veterinary graduate, but also the problem-solving and technical skills, as well as the professional behaviours and attributes that such graduates need. Content revision has aimed, as a minimum, to meet the OIE Day-1 competencies, whilst more broadly aiming to equip graduates for the demands that will be placed upon the profession in Sri Lanka for the next 20 or so years. Pedagogical revision has been based upon current best practices in veterinary medical education worldwide, and the revision of clinical teaching has aimed to draw upon the breadth of clinical resources that are available throughout the country. Presentation of the curriculum proposals to the veterinary profession and its stakeholders has been met with a high level of assent, including willingness to participate in clinical teaching of the extended final year. The hope of the FVMAS is that this review will equip the next generation of veterinary graduates to meet the needs of the animal owners of Sri Lanka and, hence, for the Sri Lankan veterinary profession to be recognized as one of the most outstanding in the region(Wijayawardhane et al., 2020).

\section{Note on implementation}

The curriculum described in this paper was launched in January 2020, to a cohort of around 100 students. The students were thoroughly briefed on the changes that had been made and of the expectations of the faculty for the new curriculum during the 
(extended) pre-vet part of the program. Academic staff had, as well as their integral involvement with the design process, been provided with a lengthy training program in the pedagogical methods that were needed to underpin the curricular changes (see McIntyre and Parkinson, 2020 for details). Concurrent changes to physical teaching infrastructure are further underpinning implementation of the new curriculum, although they are beyond the scope of the present paper.

\section{REFERENCES}

Anderson, L.W. and Krathwohl, D.R. (2001). A taxonomy for learning, teaching, and assessing: a revision of Bloom's taxonomy of educational objectives. Addison Wesley Longman, New York, USA.

Australasian Veterinary Boards Council (2016). Accreditation Standards. https://avbc.asn.au/wpcontent/uploads/documents/public/AVBCStandards Aug2016.pdf. Accessed 18-05-2020.

Biggs, J. and Tang, C. (2011). Teaching for quality learning at university. 4th Ed. Open University Press, Berkshire, UK.

Bok, H.G.J. and Jaarsma, A.D.C. (2017). Competencybased education. In: Veterinary medical education: a practical guide. Hodgson, J.L. and Pelzer, J.M. (Eds). Wiley-Blackwell, Ames, Iowa, USA, pp. 24-35.

Burt, G.J. (2017). Business and practice management skills. In: Veterinary medical education: a practical guide. Hodgson, J.L. and Pelzer, J.M. (Eds). Wiley Blackwell, Ames, Iowa, USA, pp. 479-493.

Dale, V.H.M., Sullivan, M. and May, S.A. (2008) Adult learning in veterinary education: theory to practice. Journal of Veterinary Medical Education, 35, 581-588.

Danielson, J. and Hecker, K. (2017). Concepts in assessment. In: Veterinary medical education: a practical guide. Hodgson, J.L. and Pelzer, J.M. (Eds). Wiley Blackwell, Ames, Iowa, USA, pp. 219-236.

Davis, M.H. (2003). Outcome-based education. Journal of Veterinary Medical Education, 30, 25863.

Harden, R.M., Sowden, S. and Dunn, W.R. (1984). Educational strategies in curriculum development: the SPICES model. Medical Education, 18, 284-97.
Hinchliffe, S. (2015). More than one world, more than one health: Re-configuring interspecies health. Social Science \& Medicine, 129, 28-35.

Hodgson, J.L. and Ilkiw, J.E. (2017). Curriculum design, review and reform. In: Veterinary Medical Education: A Practical Guide. Hodgson, J.L. and Pelzer, J.M. (Eds). Wiley-Blackwell, Ames, Iowa, USA, pp. 3-23.

Inzana, K.D. (2017). Curriculum mapping. In: Veterinary Medical Education: A Practical Guide. Hodgson, J.L. and Pelzer, J.M. (Eds). WileyBlackwell, Ames, Iowa, USA, pp. 36-42.

McIntyre, L.H. and Parkinson, T.J. (2020). Leading significant institutional change in the context of an OIE-endorsed Veterinary Twinning Project. Journal of Veterinary Medical Education, Advanced online publication at: https://doi.org/10.3138/jvme.2019$\underline{0125}$

Miller, G.E. (1990). The assessment of clinical skills/competence/performance. Academic Medicine, 65, s63-67.

Newble, D., Stark, P., Bax, N. and Lawson, M. (2005). Developing an outcome-focused core curriculum. Medical Education, 39, 680-687.

OIE (2012). Recommendations on the Competencies of Graduating Veterinarians (Day 1 Graduates) to assure National Veterinary Services of Quality (May, 2012). OIE.

http://www.oie.int/fileadmin/Home/eng/Support to OIE_Members/Vet_Edu_AHG/DAY_1/DAYONE -B-ang-vC.pdf. Accessed 18-05-2020.

OIE (2013). A Guide to Veterinary Education Twinning Projects (September, 2013). http://www.oie.int/fileadmin/Home/eng/Support to OIE_Members/Vet_Edu_AHG/GuideVetEducatio n_ANG 21012013.pdf. Accessed 18-05-2020.

Parkinson, T.J. (2017). Learning in real world settings. In: Veterinary Medical Education: A Practical Guide. Hodgson, J.L. and Pelzer, J.M. (Eds). Wiley-Blackwell, Ames, Iowa, USA, pp. 196216.

Prideaux, D. (2003). Curriculum design: $A B C$ of learning and teaching in medicine. British Medical Journal, 326, 268-270. 
Pritchard, W.R. (Ed.) (1988). Future Directions for Veterinary Medicine: Report of the Pew National Veterinary Educational Program, Duke University, Durham, NC, USA.

Ranaweera, N.F.C. (2007). Sri Lanka: Opportunities for dairy sector growth.

http://www.fao.org/3/i0588e/i0588e08.htm. Accessed 18-05-2020.

RCVS standards and procedures for the accreditation of veterinary degrees (2017).

https://www.rcvs.org.uk/document-library/rcvsaccreditation-standards/Accessed 18-05-2020.

Schwabenbauer, K. and Rushton, J. (2007). Veterinary services for poultry production. In Proceedings of the International Conference Poultry in the Twenty-first Century: avian influenza and beyond, held 5-7 November 2007, Bangkok, Thailand. http://www.fao.org/3/a-i0323e.pdf Accessed 28-09-2020.

Sri Lanka Qualifications Framework (2012). Ministry of Higher Education, Sri Lanka. https://www.eugc.ac.lk/qac/downloads/SLQF_2016 en.pdf. Accessed 31-07-2020
Van de Mortel, T.F. and Bird, J.L. (2010). Continuous curriculum review in a bachelor of nursing program: preventing curriculum drift and improving quality. Journal of Nursing Education, 49, 592-595.

Welsh, P.J.K., Jones, L.M., May, S.A., Nunn, P.R., Whittlestone, K.D. and Pead, M.J. (2009). Approaches to defining day-one competency: a framework for learning veterinary skills. Scientific and Technical Review of the Office International des Epizooties, 28, 771-777.

Wijayawardhane, N., Rabel, C., McIntyre, L., Parkinson, T.J., Ariyarathne, S. and Abeygunawardena, H. (2020). Institutional Experience with Curricular Renewal during the OIE Veterinary Education Twinning Program between the University of Peradeniya, Sri Lanka, and Massey University, New Zealand. Journal of Veterinary Medical Education, Advanced online publication at: https://doi.org/10.3138/jvme-2019-0113

Wilson, E.A., Rudy, D., Elam, C., Pfeifle, A. and Straus, R. (2012). Preventing curriculum drift: sustaining change and building upon innovation. Annals of Behavioral Science and Medical Education, 18, 23-26. 